\title{
La enseñanza del
}

Derecho en

\section{Estados Unidos}

Miembro del grupo investigador de la red española «Derecho y Sociedad». Profesor titular de la Universidad de Alicante (Madrid)

El presente artículo hace parte del texto «La enseñanza del Derecho en Estados Unidos» en el que se hace alusión a los aspectos "sustantivos" de la misma enseñanza: Qué es lo que ocurre "puertas adentro" en las aulas, es decir, qué se enseña y cómo se enseña, cúales son los métodos-ftécnicas pedagógicas, materiales bibliográficos, sistemas de evaluación) y contenidos (orientación de la enseñanza, plan de estudios,etc.) de la docencia.

\section{ASPECTOS SUSTANTIVOS: MÉTODOSY CONTENIDOS DE LA ENSEÑANZA DEL DERECHO EN ESTADOS UNIDOS}

\section{a) EI "Case method» $y$ sus orígenes.}

A principios del siglo XIX no existían los estudios de Derecho tal como los conocemos hoy. Como ya he apuntado, los abogados se formaban trabajando como pasantes, y aprobar el «Bar exman» - en aquellos Estados que le exigían - era poco más formalidad.(5t) En este contexto surgieron las primeras escuelas de Derecho, de carácter no universitario, cortadas según los que podríamos denominar el «Modelo Litchfield"(52). En América siempre había habido abogados que se formaban especialmente en serio la tarea de enseñar a sus pasantes. Algunos dedicaban cada vez mas tiempo a esa labor y menos a sus clientes, admitían a un número cada vez mayor de pasantes e incluso comenzaba a cobrarles por ese aprendizaje, hasta que finalmente abandonaba el ejercicio de la profesión y su bufete se convertía en una escuela de abogados. Así surgió la célebre escuela de Litchfield (Connecticut), fundada en 1784 por el juez Tapping Reeve, y que puede considerarse la primera «Facultad" de Derecho de Estados Unidos; funcionó hasta 1833. La enseñanza en este tipo de escuelas, con escasos medios, sin requisito de admisión ni exámenes finales, duraba poco más de un año, y estaba exclusivamente orientada a la práctica. Pero el método docente incluía a menudo el de las conferencias, de las que los alumnos tomaban apuntes.

El «Modelo Litchfield» terminó siendo absorbido por la enseñanza del Derecho de carácter Universitario, inaugurado con la creación en 1817 de la primera facultad (ya sin comillas) de Derecho en la Universidad de Harvard. Aquí el modelo era Blackstone. Las conferencias que Blackstone impartió en Oxford a mediados del siglo XVIII, y que fueron la base de sus famosos Commentaries, en realidad no había sido pensadas para la formación de juristas en la Universidad, sino para un público muy amplio, pero las facultades de Derecho 
siguieron su ejemplo y los Commentaries pronto se convirtieron en la «Biblia» de la enseñanza del Derecho tanto en Inglaterra como en Estados Unidos.

He afirmado que el modelo Litchfield fue «absorbido» - mas que «sustituido» por el modelo de Blackstone. Con ello quiero decir que, durante buena parte del siglo XIX, la enseñanza «universitaria» del Derecho, aunque con pretensiones intelectuales algo más ambiciosas que la de Litchfield, seguía arrastrando muchos de los rasgos del modelo anterior. Su nivel era bastante pobre, no había exámenes de ingreso ni de fin de curso (bastaba con pasar por ahí dos años y pagar la matrícula) y, sobretodo, la enseñanza seguía estrechamente orientada a la práctica profesional: estaba concebida más como un aprendizaje técnico en una escuela de capacitación profesional que como una disciplina académica «respetable» que se enseña en la universidad.

En realidad, la enseñanza universitaria del Derecho, tal como se entiende hoy comienza a configurarse a partir de 1870 . En ese año un abogado de Nueva York Ilamado Chritopher Columbus Langdell (1826 - 1896) fue nombrado primero profesor y meses después Decano de la Facultad de Derecho de Harvard (antes, la figura del Decano no existía). Langdell llevó a cabo una auténtica revolución en la enseñanza del Derecho.

Como Decano de Harvard, la obsesión de Langdell era precisamente reinvindicar esa respetabilidad académica de la que carecía hasta entonces el estudio del Derecho en su país. Langdell sostiene una y otra vez que el Derecho es una "ciencia», aunque nunca sabremos nosotros con seguridad si es de esa creencia sincera en la cientificidad del Derecho de donde surgen su empeño por elevar el rango académico de los estudios jurídicos o si, por el contrario, la invocación de la idea de ciencia no es mas que una estrategia retórica para alcanzar dicho objetivo. En un discurso pronunciado en 1886 durante la conmemoración del 250 aniversarios de la fundación del Harvard College, Langdell insiste en que «el Derecho es una ciencia», y añade: «si el Derecho no fuera una ciencia, más le valdría a la universidad hacer honor a su propia dignidad renunciando a su enseñanza. Si no fuera una ciencia, entonces es una especie de artesanía, y la mejor manera de aprenderla será sirviendo como aprendiz de alguien que los practique. Pero si fuera una ciencia, entonces difícilmente podrá discutirse que se trata de una de las más nobles y difíciles de entre las ciencias, y que precisa toda la luz que el más ilustrado centro del saber pueda arrojar sobre ella». En este sentido, la contribución de Langdell al fortalecimiento institucional de la enseñanza del Derecho fue muy notable: entre otras cosas, elevó los estándares para la admisión de estudiantes, introdujo un riguroso sistema de exámenes, sentó las bases de la mayor biblioteca jurídica del mundo, reclutó a un claustro de profesores de excelente calidad, y creó la figura del catedrático profesional de Derecho(53)). En suma, Langdell creó el modelo de las facultades de Derecho americanas como las grandes instituciones educativas que antes he descrito. Pero no son estas reformas «institucionales" las que ahora nos interesan, ni tampoco son ellas la razón principal por la que este personaje ha pasado a la historia(54). La verdadera «revolución» de Langdell hay que buscarla en los contenidos y métodos docentes.

Langdell no sólo reaccionó contra el enfoque «artesanal» del modelo Litchfield, sino también y especialmente contra el modo dominante en la enseñanza universitaria del Derecho de su época, que como hemos visto era la lección magistral al estilo Blackstone. Él habia llegado a la conclusión de que el estudio científico del Derecho debía consistir en el dominio de un número relativamente reducido de principios o doctrinas básicas, y de que la vía rápida y segura de alcanzar ese dominio era el análisis de una serie de "casos" o sentencias judiciales cuidadosamente seleccionada, en las que esos principios y doctrinas toman cuerpo. En consecuencia, el método de enseñanza del Derecho debía centrarse en el estudio de esos casos: el "case method".

También en este terreno estrictamente de la docencia llevó Langdell a la práctica sus ideas: como profesor de Derecho de Contratos elaboró una compilación sistemática de las primeras sentencias de los tribunales de apelación ingleses y americanos en esta materia, compilación que publicó en 1871 con la intención de que sivviera como instrumento de estudio para sus alumnos. Había nacido el primer «casebook»(55).

Langdell creía además que la docencia debía desarrollarse de tal manera que los alumnos «pudieran sacar mayor aprovechamiento de la asistencia a clase que dedicando el tiempo al estudio privado". En efecto, una vez que los 
estudiantes disponían de un libro de casos el paso siguiente tenía que ser el abandono de la tradición conferencia o lección magistral: se podía exigir a los estudiantes que leyeran cuidadosamente los casos previamente asignados para cada clase, de manera que, en lugar de «tomar apuntes», el tiempo de ésta se dedicara a la discusión colectiva de esos casos bajo la dirección del profesor. Éste debería orientar el debate planteado a los estudiantes las preguntas pertinentes para, entre todos, llegar a las conclusiones "correctas». Esta forma de dar clase se conoce en las facultades de Derecho americanas bajo el nombre, en tanto pretencioso, de «método socrático».

Estas tres novedades ("case method", "casebook", y "socratic method") encontraron una fuerte resistencia durante bastantes años, pero poco a poco fueron imponiéndose, y hacia la tercera década del presente siglo el case method (nombre que, en sentido amplio, englobaría a las tres) era ya practicado en la mayoría de las facultades de todo el país(56). Hoy en día puede decirse que el modelo de enseñanza del Derecho dominante en Estados Unidos sigue siendo el inspirado por Langdell. En realidad - y pese a las muchas críticas y debates en torno al case method, intentos de reforma y propuestas de alternativas pedagógicas-, déspués de más de un siglo apenas cabe hablar de cambios verdaderamente radicales en la enseñanza del Dérecho en este país. Las ideas de Langdell tanto las relativas al diseño institucional de las facultades de Derecho como las de su modelo docente, configuraron lo que ha dado en llamarse "ortodoxia» (58) que, con la inestimable ayuda de Harvard como su principal guardián, todavía hoy sigue gozando de muy buena salud.

Sentado esto, es necesario advertir de inmediato que el case method, tal como lo concibió Langdell, sí ha experimentado algunos cambios importantes. Si, generalizando mucho, cabe hablar de algo así como una «línea de evolución» del case method, ésta podría sintetizarse como la de una cierta tendencia hacia la «sustantivización», o al menos hacia la moderación de su formalismo inicial(59).

Como espectadores europeos formados en la tradición continental, a primera vista las reformas de Langdell quizá no nos parezcan - al menos para su época - la expresión de un enfoque excesivamente «formalista» del Derecho y de su estudio, sino más bien todo lo contrario. Al fin y al cabo, el case method pone el énfasis en las sentencias concretas de los jueces más que en las reglas generales y abstractas del Derecho legislado; en el estudio de fuentes primarias en lugar de manuales doctrinales; en la discusión participativa en las aulas en lugar de la pasividad y el dogmatismo de la lección magistral; en la formación metodológica y en la capacidad de argumentación jurídica en lugar de la simple memorización de información acerca de reglas $y$ doctrinas previamente sistematizadas. $Y$, sin embargo, Langdell ha sido y sigue siendo considerado en América el principal representante de ese enfoque acerca del Derecho vagamente etiquetado como "formalista". Para autores como Holmes y como Frank, Langdell simbolizaba explícitamente la encarnación del «enemigo" ¿cómo se entiende esto?.

En primer lugar, creo que conviene introducir aquí, a modo de recordatorio, una advertencia general acerca de algo que es tan sabido como frecuentemente olvidado. La cultura jurídica americana ha sido siempre - y no sólo a partir de los realistas - muchísimo más "sustantivas" o antiformalista que la europea continental, e incluso más también que la inglesa(60). En comparación con Europa la variable, llamémosla así, «formalismo/realismo» está en América mucho más "desplazada" en bloque hacia el segundo de estos polos, de manera que lo que a nosotros puede parecernos una posición mas bien "sociologista", "antinormativista», "realista», o como se la quiera llamar, en América lo es mucho menos; y viceversa, allí tacharían de «formalista" o "positivista» a posturas que para nosotros no lo son tanto (esto último es un poco lo que ocurre con Langdell). Uno nunca termina de acostumbrarse del todo a la paradoja de que sea en un país con este tipo de "cultura" o "tradición" jurídica donde precisamente se desarrollaran las criticas mas feroces contra el formalismo: al leer los texto de los realistas uno no puede dejar de pensar que donde verdaderamente muchas de esas criticas serían pertinentes es en Europa, y no (o mucho mas que) en Estados Unidos. Si Langdell era para Holmes "el mayor teólogo jurídico vivo", ¿qué no diría de la "escuela de la exégesis" o de la «jurisprudencia de conceptos»?(61). Por otra parte, no debemos dejarnos seducir demasiado por el tinte «judicialista" que se podría percibir en una orientación que, como el case method, gira en torno a las sentencias de los tribunales. Como ya había dicho Bentham años atrás, en el sistema del "Common Law» los jueces elaboran 
las normas «como lo haría un hombre para con su perro: cuando se quiere impedir que el perro haga algo que el dueño no quiere, se espera hasta que lo haga, y entonces se le castiga por ello»(61). Así como en un país de "Common Law» como Estados Unidos, si puede triunfar en enfoque de tipo formalista, éste ha de ser sobre todo un «formalismo jurisprudencial», y cualquier orientación de carácter «judicialista» no tiene exactamente las mismas connotaciones antiformalistas que tendrían en la Europa continental.

Una vez situados en este contexto hay que decir que la concepción del case method de Langdell responde efectivamente a una visión formalista. «Formalista» al menos en dos sentidos. En primer lugar, y como se desprende claramente del largo pasaje que antes he reproducido,(63) el estudio de sentencias judiciales concretas no es más que la vía para extraer y construir, a partir de ese material en bruto y desordenado, un sistema lógicamente consistente de principios y doctrinas generales, que es en lo que verdaderamente consiste el Derecho, no siendo esas sentencias mas que sus manifestaciones particulares. Como dice Homes, «el ideal jurídico del Sr. Langdell, la finalidad de todos sus esfuerzos, es la elegantía juris o la integridad lógica del sistema en cuanto sistema. El es, quizá, el mayor teólogo jurídico vivo.Pero, como teólogo, no está tan preocupado por sus postulados como por mostrar que las conclusiones derivadas de ellos permanecen ligadas entre sí»(64). El case method de Langdell implica pues la sistematización del Derecho mediante un análisis neutral, donde las ideas de orden, sistema, taxonomía y simplicidad juegan el papel central. Haciendo abstracción de las circunstancias concretas que se deciden en el contexto particular de cada caso, el estudio de una sentencia debía dirigirse más bien al principio jurídico subyacente a su «ratio decidendi». Los principios así extraídos podrían después aplicarse casi mecánicamente (“con constante facilidad y seguridad", decía Langdell) a nuevas situaciones, debiendo el juez respetar escrupulosamente la doctrina del precedente ("stare decisis»). A los pocos casos particularmente importantes que debían incluirse en un "casebook» se les atribuía pues un carácter normativo general que los hacía susceptibles de un tratamiento casi tan "formalistas", aunque fueran sentencias judiciales, como el que daría un jurista continental de aquella época a los artículos de un código.(65)
En segundo lugar, el case method diseñado por Langdell era "formalista" en el sentido de que aislaba herméticamente el estudio del Derecho tanto respecto del «sucio mundo del ejercicio profesional»(66) como de las demás disciplinas sociales. Esto es consecuencia de su visión del Derecho como "verdadera ciencia», que debía firmar su autonomía, su «pureza» en el sentido del positivismo jurídico más estrecho.(66) El Derecho solo consta de principios y doctrinas jurídicas, y en las facultades de Derecho la dieta exclusiva de los estudiantes debía estar compuesta por los casos en que éstas aparecen. La ciencia política, la historia, la sociología o la economía debian confinarse en otros departamentos de la universidad. La experimentación empírica y cualquier referencia al entorno social quedaban desterradas de la facultad de Derecho. Dicho con otras palabras, Langdell es el padre del llamado «paradigma del Derecho en los libros».(68)

\section{b) El "case method" en la actualidad.}

Me he detenido explicar la orientación del case method en su versión original la de Langdell no simplemente como curiosidad histórica. En la medida en que, como he dicho, la "ortodoxia" la de Langdell sigue fundamentalmente vigente, también siguen siendo pertinentes muchas de las criticas a su formalismo. que le dieron los realistas, o las que más o menos vagamente inspiradas en éstos se les dirigen todavía hoy. Ahora bien: que la «revuelta contra el formalismo" protagonizada por los realistas estuviera lejos de triunfar plenamente no significa que sus criticas, a Langdell no dejaran huella alguna. No puedo detenerme aquí en esas criticas, pero sí debo entrar a describir con algo mas de detalle cómo funciona hoy el case method después del - para algunos todavía insuficiente - impacto del realismo, que sin duda sí ha conseguido como mínimo moderar su formalismo.

Una de las modificaciones más llamativas que ha experimentado el case method después de los años 30 afecta a los instrumentos empleados en la enseñanza. Los "casebooks", que antes solo contenían sentencias de los tribunales de apelación(69) , ahora suelen además incluir, entre otros materiales, comentarios y preguntas planteadas al estudiante por el propio compilador, fragmentos de las actuaciones del proceso en primera instancia, textos legales (obligada respuesta al enorme incremento de la proporción del Derecho legislado respecto del jurisprudencial 
desde los años de Langdell hasta hoy), formularios, fragmentos, libros o artículos jurídicos escritos por académicos y, lo que es más importante, textos y notas del propio autor o de otros especialistas relativos a aspectos sociológicos, económicos, filosóficos, históricos, etc. relevantes para el caso en cuestión. El tradicional «casebook» ha sido pues sustituido, en muchos casos, por publicaciones que suelen llevar et más descriptivo título de "cases and materials».

La incorporación al "casebook" de otras disciplinas distintas del Derecho puede entenderse como el resultado directo de la influencia ejercida por la jurisprudencia sociológica y el realismo jurídico.(70)

En general, el carácter cerrado de la enseñanza del Derecho como ciencia autónoma a dado paso a una orientación cada vez mas interdisciplinaria. Síntoma de ello es la proliferación más o menos reciente de escuelas o movimientos que defienden la introducción de diversos enfoques acerca del Derecho y su docencia desde o en conexión con otras disciplinas. Me refiero a los movimientos que suelen bautizarse con el nombre de "Law and...": "Law and Society", "Law and Economics", "Law and Literature", "Law and Psychology", etc(71). Estas tendencias han logrado consolidar su presencia - unas mas que otras - en el curriculum de cursos ofrecidos por muchas facultades, y aunque siguen situadas en la periferia mas que en el centro de la enseñanza del Derecho, su influencia también se ha dejado notar en los contenidos y en el estilo docente algo mas abierto a consideraciones «extrajurídicas» que presentan hoy los estudios dogmático - jurídicos que tradicionalmente ocupan el centro (los análisis centrados en la llamada «Legal doctrine»).(72)

De todas formas, el énfasis de la enseñanza del Derecho sigue recayendo en el estímulo y desarrollo de las «facultades", "habilidades» o "técnicas» que caracterizan propiamente el trabajo del "jurista". En América suele emplearse una expresión que sintetiza el sentir generalizado acerca de qué es lo que deben enseñar las facultades de Derecho: a «pensar como juristas". La idea es bien sencilla: a través del case method y de la «discusión socrática», lo que se busca es proporcionar una buena formación metodológica, más que la acumulación memorística de una información enciclopédica acerca de reglas y doctrinas jurídicas(73). El objetivo primordial no es tanto "enseñar normas", sino enseñar a plantear, analizar, comparar, construir y evaluar concretas situaciones fácticas y argumentos y decisiones jurídicas (sobre todo judiciales, pero también legislativas), y a «proyectar» líneas de casos y de legislación sobre situaciones nuevas(74). Se trata pues de fortalecer ante todo la capacidad de análisis y razonamiento jurídico, así como la de su expresión oral y escrita. Suele decirse además que el case method, al menos tal y como se concibe hoy, está "orientado a la resolución de problemas» («Problem - solving») por parte de los estudiantes, más que a la recepción pasiva de la doctrina: tanto o más que conocer los contenidos de soluciones concretas (que pueden variar de uno a otro Estado, de una a otra sentencia o línea jurisprudencial), los estudiantes deben aprender a discemir por sí mismos dónde están los problemas relevantes, cómo surgen y mediante qué procesos jurídicos los tribunales, los legisladores o los abogados intentan resolverlos. Interesa, en suma, que los estudiantes aprendan a hacer preguntas casi más que a saber las respuestas.

En los tiempos de Langdell, este énfasis en la capacidad de razonamiento se entendía sobre todo en el sentido de "razonamiento lógico". Entre los defensores actuales del case method todavía quedan muchos que mantienen esa fe en la suficiencia de la "razón formal» y en la aplicabilidad mecánica de los principios extraídos de los casos, con la proscripción de cualquier consideración valorativa o argumentación de carácter sustantivo. Ocurre que, invocando al prestigioso nombre del case method se han defendido y se defienden interpretaciones o aplicaciones del mismo más - menos "formalistas", más o menos "sustantivas». Cabe decir en líneas generales que, como sostienen Atiyah y Summers, el case method se ha «sustantivizado» mucho, aunque mi impresión es que no tanto como lo pintan estos autores(75). De todas formas, hay que reconocer que en la actualidad el empleo del case method ha abierto sus puertas al razonamiento sustantivo, a los argumentos materiales en términos de «policies», a la justificación de carácter social, económico y a veces incluso político y moral. Para algunos, esta «apertura» resulta todavía insuficiente. En todo caso - esto es lo que a nosotros más nos interesa aquí - en términos comparativos con la situación española el case method practicado hoy en América es sin duda un método de enseñanza mucho menos formalista y mucho más abierto a la argumentación sustantiva que el modelo estándar

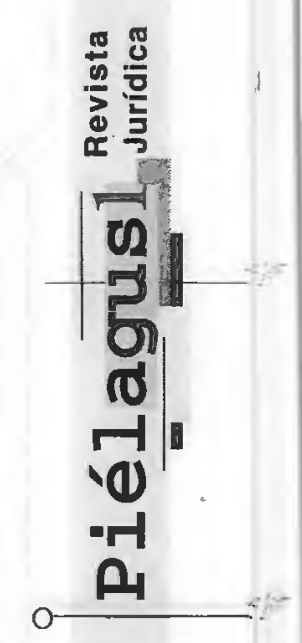


de enseñanza del Derecho en España. El «policy análisis", tanto en la docencia como en la investigación, ha sido la herencia directa sobre todo de la «jurisprudencia sociológica» de Pound, y también el legado «descafeinado» que la fuerza críticå del movimiento realista consiguió dejar tras de sí en la ciencia jurídica norteamericana. $Y$, efectivamente, en muchos casos el Derecho ya no se enseña tanto "como un cuerpo autoritario de doctrina" cuanto "como un instrumento de "policy» política, económica y social (...). Al enseñar a sus estudiantes cómo comprender el Derecho, los docentes americanos acentúan la necesidad de buscar, por detrás de las reglas impresas, los problemas subyacentes de política social y de administración práctica»(76).

\section{c) El «método socrático»}

Este enfoque «metodológico» e «instrumental» de la enseñanza del Derecho se pone de manifiesto sobre todo en las aulas, en la manera de conducir las clases a través del llamado «método socrático». En nuestras universidades solemos asumir con resignación la idea de que no hay manera humanamente posible de llevar a la práctica el formato de las «clases dialogadas" si tenemos delante un grupo de más de treinta estudiantes: cuando el grupo es muy numeroso, la única opción que le queda al profesor, le güste o no, es la lección magistral; la docenćia a través de discusiones mínimamente rigurosas debé confinarse al marco de seminarios reducidos de estudiantes voluntarios especialmente seleccionados o motivados. En Estados Unidos, los grupos de segundo y tercer año tienen esas características: los estudiantes han elegido voluntariamente todos sus cursos (no hay asignaturas obligatorias), e incluso el profesor puede establecer - con frecuencia lo hacen- un número máximo de estudiantes y determinados requisitos de admisión para su curso (por ejemplo, haber cursado previamente cierta asignatura, o una determinada orientación de su curriculum durante el College, o conocer algún idioma extranjero...). Sin embargo, el método socrático también se utiliza, y de manera especialmente «ortodoxa», en los cursos del primer año, donde todas las asignaturas son obligatorias y los grupos son de 100 ó 150 alumnos. Sorprendentemente, el sistema funciona con relativa soltura. Esto en parte se explica porque, como ya he dicho, se trata de un colectivo de estudiantes intelectualmente más maduros, con una sólida formación durante el College, dotados de espiritu crítico y participativo, acostumbrados a expresar sus conocimientos y opiniones de manera articulada, y que han superado un proceso de selección (especialmente el LSAT) precisamente dirigido a primar las cualidades más idóneas para este tipo de docencia; por su parte, los profesores generalmente dominan el difícil arte de la clase dialogada, que es el estilo de enseñanza que ellos mismos recibieron cuando fueron estudiantes y en el que están bien entrenados porque es el que han ejercido durante toda su carrera docente. Pero hay también otras razones «menos nobles» que explican el funcionamiento del método socrático. La participación del estudiante, y el buen nivel que se exige a sus intervenciones, se estimula de modo artificial porque el alumno sabe que de la frecuencia y calidad de sus actuaciones en clase depende en buena medida su nota final en esa asignatura, y porque muchas de las preguntas del examen tendrán que ver directamente con lo que ha ocurrido durante la discusión en el aula(r). La asistencia a clase es estrictamente obligatoria, y la participación de hecho casi también.

Muchas veces los estudiantes tienen asignado un asiento fijo y numerado en cada curso, y durante la clase los profesores tienen delante un diagrama del aula con los nombres de los estudiantes que ocupan cada asiento (a veces incluso con su fotografía), de manera que toman buena nota de cuánto y cómo interviene cada estudiante, e incluso pueden seleccionar a quién dirigir sus preguntas sin esperar a que aparezcan voluntarios. Por eso se ha criticado a veces el ambiente represivo y «de colegio" que el método socrático puede llegar a crear en las aulas. Una clase de este tipo se desarrollaria más o menos así: el profesor comienza su clase de seleccionando sin previo aviso a uno de sus alumnos, a quien pide que "plantee el caso", es decir, que exponga durante unos minutos la información básica acerca de los hechos, las cuestiones jurídicas que se suscitan, la argumentación utilizada y la decisión final del juez, en relación con el caso previamente asignado para ese día(rz). A continuación, ese ,mismo estudiante es sometido a un duro interrogatorio sobre lo que acaba de decir, durante el cual el profesor le va presionando para que clarifique sus respuestas, estrechándose el cerco en torno a las cuestiones más relevantes. Tarde o temprano el alumno ha quedado contra las cuerdas y se ve incapaz de responder satisfactoriamente a una pregunta, y entonces se levantan varias manos de otros compañeros dispuestos a responderla. El profesor llama a uno de ellos y continúa con él la discusión, 
aunque a veces ésta se limita a aclarar el punto problemático y se reanuda el interrogatorio del primer estudiante que puede prolongarse durante la mayor parte de la hora y medía que generalmente dura una clase. Pero lo normal es que intervengan al menos una docena de protagonistas principales, y un número mucho mayor de participantes esporádicos. Con frecuencia el profesor interrumpe el debate para introdteir una breve disertación sobre algún punto y continuar después la discusión. Al final, el profesor suele recopilar las conclusiones principales que «entre todos» han alcanzado, aunque hay profesores que se limitan a hacer preguntas y plantear problemas durante toda la clase, obligando a que cada estudiante extraiga por sí mismo sus propias conclusiones.

El ambiente entre los estudiantes en este tipo de clases casi siempre es muy competitivo, aunque esa competitividad se oculte a menudo bajo un frágil disfraz de cortesía y de falso compañerismo. La competitividad entre los estudiantes es uno de los rasgos más llamativos de toda la enseñanza universitaria americana, pero en la facultad de Derecho está especialmente acentuada. El propio sistema educativo la fomenta de manera más o menos abierta. Sin ir más lejos, en el complejo mecanismo de calificación de exámenes muchas veces la nota de cada estudiante se hace depender en parte de los resultados medios obtenidos por el grupo(79). Otro ejemplo es la organización de las «moot court competitions", en las que todos los estudiantes de primer curso están obligados a participar. Se trata de juicios simulados ante tribunales compuestos por profesores, estudiantes veteranos, abogados y jueces locales; se forman parejas de estudiantes que se enfrentan como defensores de cada una de las partes del hipotético pleito, y hay todo un sistema de eliminatorias que culmina en una «gran final» y una pareja campeona (en las «upper - roung competitions", entre estudiantes de los cursos superiores, hay incluso premios en metálico). Pero quizá la competencia más dura sea aquella que enfrenta a los mejores por el puesto más codiciado: Pertenecer al consejo de redacción de la revista de la facultad, lo cual viene a ser algo parecido - salvando las distancias - a estar inscrito en aquellos «cuadros de honor" con que se premiaba a los alumnos más destacados en nuestras escuelas. Las revistas jurídicas de facultad, incluidas las más prestigiosas como la Harvard Law Review o la Yale Law Journal, tradicionalmente son editadas por un consejo formado exclusivamente por estudiantes. Pero para pertenecer a ese privilegiado consejo hay que tener uno de los cuatro o cinco de los mejores expedientes de la clase después del primer año, y/o haber superado un durísimo examen de selección organizado específicamente para este fin. En suma, los estudiantes de las facultades de Derecho Americanas no estudian tanto para aprobar - ya he dicho que prácticamente todos aprueban - cuanto para sacar mejores notas que los demás y situarse así en los primeros puestos de su promoción (de ello depende además, no lo olvidemos, su salida profesional).

Pero volvamos al método socrático en las aulas. Ésta atmósfera general tan competitiva explica que a veces los estudiantes levanten la mano en clase no ya con la intención de participar en una sana confrontación intelectual, sino con el deseo mal disimulado de «derrotar»y, si es posible, ridiculizar ante el profesor y ante los demás compañeros a aquel que acaba de tener una intervención desafortunada o no supo contestar a la pregunta del profesor, sobre todo si este «compañero» es uno de sus más directos rivales en el ranking de su promoción: también en las intervenciones en clase el éxito depende en parte de que se haga no ya un buen papel sino un papel, mejor que el de los demás.

Así pues, el método socrático es una arma de doble filo. Por un lado, estimula sin duda la participación activa del estudiante y le acostumbra a discutir y argumentar, a manejar en público ese estilo inquisitivo de análisis característico del abogado, cosa que difícilmente puede conseguir la lección magistral. Pero, por otro lado, puede crear en algunos estudiantes (o en muchos) un sentimiento agobiante de temor ante la posibilidad de "ser llamado" por el profesor y verse expuesto así al fracaso en público, a una cierta humillación ante el profesor y ante sus propios compañeros; la asistencia a clase puede convertirse para ellos en una experiencia diaria de tensión y angustia(80), que explica la apanición de prácticas como el llamado «backbenching»(81) o el «no - hassle pass».(82)

Una ambivalencia parecida puede detectarse en uno de los rasgos más elogiados del método socrático: el espíritu crítico que inculca a los alúmnos. Efectivamente, el método socrático no solo enseña a reconstruir paso a paso el razonamiento de los tribunales, sino también a criticarlo(83). Los estudiantes deben estar preparados para emitir una opinión sobre si la decisión es correcta, y ofrecer razones para 
defender su postura; durante la discusión el profesor y los demás compañeros desafían al estudiante, presentándole contra argumentos que éste debe sopesar y criticar para seguir defendiendo su postura o para cambiarla. Incluso a veres el profesor plantea inicialmente el estudio de los casos adoptando el punto de vista de un juez que debe tomar una decisión careciendo de reglas o de precedentes judiciales aplicables a ese caso. Es verdad que el método socrático parece correr más el peligro de caer en la crítica gratuita y en la discusión chapucera de barra de bar, que en el extremo opuesto del dogmatismo propio de la lección magistral. Pero también hay que advertir que el método socrático es susceptible de un uso mucho más autoritario bajo la apariencia abierta y flexible de la discusión con los estudiantes. De hecho, este tipo de debate ha sido criticado a veces como un juego amañado en el que de antemano la posibilidad real de ganar es de un sólo jugador: el profesor. Éste somete a los estudiantes a un interrogatorio con el que poco a poco va conduciendo al rebaño hasta su redil. El profesor está en posesión de la verdad, conoce la única respuesta correcta, y todo es cuestión de que los estudiantes lleguen "por sí mismos" (?) a esa misma conclusión, en lugar de imponérsela de manera autoritaria desde un principio. El autoritarismo intelectual queda así demagógicamente disfrazado. Al final, si alguien no entra en el redil es porque no ha sido capaz de seguir correctamente todos los pasos dados en clase, y pełmanecerá por tanto en el error.

\section{d) El «Curriculum».}

Por último, unas palabras sobre el contenido del «curriculum» o plan de estudios. Pese a la heterogeneidad de facultades $y$, dentro de cada una, la variadísima oferta de cursos optativos, en la práctica se puede hablar de ciertos rasgos generales comunes que nos permiten estructurar la descripción de lo que sería el plan de estudios estándar. Esa estructura podría verse como una especie de «precipitado» de la historia jurídica (o de la historia, a secas) de Estados Unidos desde los tiempos de su primer diseñador Langdell. Cada uno de los tres años de que consta el curriculum reflejaría un período distinto:

1. En el primer año se incluyen con carácter obligatorio, las «grandes instituciones» 0 sectores tradicionales del «Common Law", el edificio básico del Derecho correspondiente al liberalismo económico de finales del siglo XIX: «contratos»,
"Torts», «propiedad», «Procedimiento Civil» y «Derecho Penal». Como se ve,se trata básicamente de Derecho privado (con el Derecho Penal como «gendarme»). La fuente casi exclusiva es la jurisprudencia de los tribunales el «boom» del derecho legislado vendrá después), por lo que aquí el case method campa por sus respetos más que en ninguna otra parte. Y además, enfocado a la manera clásica, como un ejercicio de «razonamiento jurídico» entendido sobre todo en el sentido de razonamiento «formal», de sujección al precedente, de búsqueda de la «lógica interna" de cada sector de la doctrina que se plasma en una «línea de casos» bien estructurada (aquí si hay que memorizar casos emblemáticos y sus principios o doctrinas). Los argumentos de «policy» juegan un papel mucho menor. Langdell vive.

2. En el segundo y tercer año todos los cursos son optativos (salvo el relativo a la regulación y deontología del ejercicio profesional, exigido para tal acreditación). La cantidad y variedad de las ofertas es enorme (no es raro que supere el centenar, aunque la facultad suele proponer «bloques» con un vago perfil o recomendar encarecidamente algunos cursos). En esta maraña se pueden distinguir no obstante dos grandes "tipos" de cursos. Estos dos tipos no necesariamente corresponden respectivamente al segundo y tercer año (se trata de "ganar» un cierto número de "créditos", distribuyéndose el estudiante las materias - salvo algunas «incompatibilidades»-como prefiera), aunque, dadas las costumbres que los estudiantes siguen al elegir, quizá también se puedan distinguir por años. El primer tipo (o el segundo año de carrera) sería el heredero de la jurisprudencia sociológica y del realismo jurídico, expresaría el programa «reformista» del New Deal, y mostraria la estructura burocrática y la función intervencionista y reguladora del Estado del Bienestar. Aquí se estudian cursos sobre Derecho tributario, Derecho del Trabajo y de la Seguridad Social, Derecho Antitrust, Derecho

Administrativo... es decir, Derecho público y legislado. También entraría aquí en general el estudio de la reglamentación pública del mundo económico: Derecho de 
sociedades («Corporations»), regulación de mercados financieros ( «Securities

Regulation", "Acquisitions and Mergers", Banking Regulations", Corporate

Transactions", ...), comercio internacional, Derêcho concursal, etc. En la docencia de estos cursos entran mucho más que antes las consideraciones de epolicy».

3. Fìnalmente, hay un segundo tipo de cursos optativos (a menudo "seminarios")que lamentablemente se suelen relegar para el tercer año, algo más relajado porque hay que ir ya preparando el «Bar exam» $y$ entrevistándose para un trabajo. Figuran a veces en el catálogo pensando también en quien quiera continuar con un Master o un Doctorado. Se trata de cursos sobre materias tales como historia del Derecho, filosofía del Derecho, Derechos humanos, ciencia política, Teoría Social, Derecho comparado, etc. aquí se ubicarían también las "nuevas ramas" del Derecho, o el estudio de instituciones más recientes, herederas esta vez de lo movimientos sociales de los años 60 (Derecho del Medio ambiente, de la salud, del deporte, de los consumidores, «public interest Law", asisitencia jurídica a los necesitados - « Legal Services»-, Derecho cổntra la discriminación racial y sexual, Derecho urbanístico, informática jurídica, etc.), así como los cursos de "Law and..." ("Law and Society", "Law and Econiomics", "Law and Literature", "Law and Education»; «Law and Psychology», etc.) y cursos de prácticas como la llamada «Clinical legal education» o la "alternative dispute resolution" (negociación, mediación, arbitraje). El enfoque de este tipo de estudio sestá también orientado a la "policy science», pero esta vez con un bagaje metodológico interdisciplinar mucho mayor, y a menudo se plantan cuestiones valorativas, de índole moral y política, que en los otros cursos apenas se suscitan o no se abordan abiertamente.

4. Valoración general La valoración global de la anterior visión de la enseñanza del Derecho en Estados Unidos arroja un balance claramente positivo. Aunque los profesores de Derechos Americanos siguen discutiendo mucho sobre estos temas, creo que en el fondo late casi siempre una cierta sensación de "complacencia» ante la calidad y ante la orientación pragmática, flexible, interdisciplinar, crítica, etc; que ha adquirido hoy la enseñanza del Derecho (la formación de "verdaderos juristas") en Estados Unidos. Para alguien venido de España, la visión puede llegar a ser aún más optimista. No se me escapa que el lector haya podido percibir cierta carencia de sentido crítico en toda mi anterior exposición, y que a medida que la iba leyendo quizá estuviera pensando, algo molesto, que yo le estaba dibujando un panorama paradisíaco de «lo bien que hacen las cosas los americanos" en claro contraste con «lo mal que las hacemos aquí». Yo no creo que América sea el paraíso, pero, en cuanto a la enseñanza del Derecho, pienso que uno puede y debe ser menos crítico con ella si la compara (es lo que je intentado hacer yo) con la situación en España, que en esto sí es, o está cerca de ser, el infierno. Piense el lector en las tres variables básicas en las que se puede establecer una comparación, y que sintetizarían mi anterior caracterización de los aspectos sustantivos (dejemos de lado los institucionales, donde la comparación es quizá más difícil) de la enseñanza del Derecho en América. Ésta es sin duda, respecto de la española: 1) más metodológica y menos memorística; 2) más sustantiva e interdisciplinar y menos formalista y cerrada; 3 ) más crítica (o participativa, o activa) y menos dogmática (o pasiva). Por supuesto que aún podría ser mucho más metodológica, mucho más sustantiva, mucho más critica.

Precisamente, quisiera concluir recordando al lector que, pese a todo, en Estados Unidos hay un número significativo aunque minoritario, de académicos profundamente descontentos con la enseñanza del Derecho en su país. A penas puedo siquiera enumerar una muestra de los frentes de crítica, de los cuales sólo dos o tres han sido insinuados en las páginas anteriores (mi objetivo en este trabajo no era entrar en esos debates, sino simplemente ofrecer una mínima información previa a los mismos).(84)

Una vez más - al igual que ocurría con los ataques de los realistas al formalismo de 
Langdell-, los españoles descubrimos que bastantes de esas criticas estarian mucho más justificadas en España; y tanto es así, que acaba por parecernos que en América no lo están en absoluto. Yo no pienso que esas críticas al sistema Americano sean del todo absurdas, y algunas creo que son muy pertinentes. Lo que ocurre es que tanto mi visión como mi valoración de la enseñanza del Derecho en Estados Unidos están teñidas por una comparación, aunque sea casi inconsciente, con la situación española. Pero el suelo del que parten esos críticos no es el español, sino exclusivamente el americano; $y$ desde ese contexto, tradicionalmente mucho más «sustantivo" y flexible que el nuestro, la enseñanza del Derecho dominante les parece mucho menos metodológica - interdisciplinar crítica, etc. que a nosotros, y la crítican. Como en tantas otras cosas, tampoco en la enseñanza del Derecho es oro todo lo que brilla en América. Pero, de momento, yo me daría por satisfecho si al menos lográramos pulir nuestra enseñanza hasta alcanzar un brillo semejante al Américano. Aunque sólo fuera el pálido brillo de una bisutería informal diseñada para vestir con tejanos.

\section{Notas}

51 Para entender el carácter particularmente abierto del acceso a la abogacía en estos años hay que tener en cuanta que la primera mitad del siglo XIX fue la época de la llamada "democracia jacksoniana" (Andrew Jackson fue Presidente entre 1828 y 1836). El populismo igualitarista y anti-elitista de esta doctrina política exaltaba las virtudes del "hombre medio" americano, e implicaba que todo buen ciudadano tenía algo así como un derecho innato al ejercicio de la profesión jurídica. La Constitución del Estado de Indiana es un buen ejemplo de este espiritu jacksoniano; en ella se establecía que «toda persona de buen carácter moral, siendo votantes, tendrá derecho a ser admitido a la práctica del Derecho en todos los tribunales de justicia». Véase Benson, Lee, The Concept of Jacksonian Democracy, Princeton, 1961.

52 Véase Friedman, Lawrence M., Introducción al Derecho Norteamericano, trad. Cast. De Joan Vergé i Grau, Librería Bosch, 1988, pp. 402. He acudido a este texto para relatar la etapa inicial de este breve recorrido histórico.

${ }^{53}$ Antes de Langdell, los profesores de Derecho, incluidos los que enseñaban en la universidad, eran jueces y abogados dedicados a la docencia sólo como actividad secundaria. Como Decano de Harvard, Langdell contrató a James Barr Ames, un brillante licenciado recién salido de la facultad y sin ninguna experiencia profesional como abogado: para Langdell, la enseñanza del Derecho, en cuanto ciencia, debía ser impartida por expertos en esa disciplina, independientemente de que hubieran ejercido o no la profesión.

${ }^{54}$ No cabe duda de que la orientación "práctica" de la enseñanza deł Derecho en Estados Unidos sigue siendo hoy mucho más marcada que en países como España. No por casualidad las facultades de Derecho americanas todavía se denominan "escuelas» de Derecho, al igual que las demás escuelas de enseñanzas profesionales (Medicina, Empresariales, Ingeniero...), independientes de los «Departamentos» de la universidad. $Y$ es que el objetivo primordial no es tanto cultivar intelectualmente una disciplina "científica", cuanto preparar profesionales con una buena formación técnica para el ejercicio del Derecho. Como señala Twining (op. Cit, supra nota 19), Langdell.sortea la posible tensión entre estos dos objetivos al afirmar, como veremos, que «el verdadero jurista» es aquél que domina los principios jurídicos de tal manera que es capaz de aplicarlos "con constante facilidad y seguridad a la madeja siempre enredada de los asuntos humanos".

${ }^{55}$ En el "Prefacio» de esta obra, Langdell escribe uno de los párrafos más citados a la hora de explicar los orígenes y el espíritu del "case method»: «El Derecho, considerado como una ciencia, consiste en ciertos principios o doctrinas. Lo que define a un verdadero jurista es poseer la maestría suficiente sobre estas doctrinas como para ser capaz de aplicarlas con constante facilidad y seguridad a la madeja siempre enredada de los asuntos humanos; es por ello que adquirir esa maestría debe ser la tarea de todo buen estudiante de Derecho. Cada una de estas doctrinas ha llegado a su estado actual a través de una lenta progresión; es decir, se trata de un crecimiento, que en muchos casos se extiende durante siglos. Por lo general, este crecimiento puede ser rastreado a través de una serie de casos; y la forma con mucho más rápida y mejor, si no la única, de dominar eficazmente la doctrina es estudiando los casos en que ésta se encarna. Pero los casos que son útiles y necesarios para este propósito en la actualidad guardan una proporción sumamente pequeña en relación con todos los que se han registrado. La inmensa mayoría son inútiles, o peor que inútiles, para cualquier propósito de estudio sistemático. Por otra parte, el número de doctrinas jurídicas fundamentales es mucho menor de lo que comúnmente se cree; las muchas guisas diferentes en que la misma doctrina está constantemente haciendo su aparición, y la gran medida en que los tratados jurídicos son una repetición unos de otros, son causa de muchos malentendidos. Si estas doctrinas pudieran ser clasificadas y dispuestas de forma tal que cada una pudiera encontrarse en su lugar apropiado, y no en otro, dejarian de ser 
formidables en número». Langdell, Christopher Columbus, A Selection of Cases on the Law of Contracts, viii (1871).

${ }^{56}$ A esta expansión sin duda contribuyó decisivamente el hecho de que el case method irradiara desde Harvard Law School, que por entonces ejercía desde hacia ya años un claro liderazgo entre las facultades de Derecho americanas, que por otra parte en 1871 erán sólo 31.precisamente los años de expansión del case method coinciden con un perícto de rápido fortalecimiento de la enseñanza universitaria del Derecho: entre 1870 y 1900 el número de facultades de Derecho pasó de 31 a 102. La mayoría de las facultades de nueva creación siguieron también el modelo de Harvard.

${ }^{57}$ El case method ha sido cuestionado sobre todo en dos «oleadas» críticas: la protagonizada por los realistas en los años 20 y 30 , y la de los movimientos que agitaron a toda la enseñanza universitaria durante los años 60 . Pero la discusión en torno a la enseñanza del Derecho, con mayor o menor virulencia, ha sido una constante en la cultura jurídica americana hasta nuestros días. Hoy podría hablarse de una tercera oleada de críticas que recupera muchos de los rasgos de las dos anteriores. Me refiero a la encabezada por muchos de los miembros del movimiento llamado «Critical Legal Studies". Sobre los ataques de los realistas, véase Llewellyn, Karl, «On What Is Wrong with So-Called Legal Education», 35 Columbia Law Review 653 (1935); "The Current Crisis in Legal Education», 1 Journal of Legal Education 215 (1948); The Bramble Bush. On Our Law and Its Study, 1930, 2. ${ }^{a}$ ed., 1951, Oceana, New York, pp. 192; Frank, Jerome, "Why Not"a Clinical Lawyer-School», 81 University of Pennylvania Law Review 908 (1932); Green, Leon, «A New Program in Legal Education», 17 American Bar Association Journal 299 (1931); Lasswell, Harold; McDougal, Myres, «Legal Education and Public Policy: Professional Trainingin the Public Interestn, 53 Yale Law Journal 203 (1943). Sobre las críticas de "Critical Legal Studiesn, véase Kennedy, Duncan, Legal Education and the Reproduction of Hierarchy, Afar, Cambridge, 1983; Klare, Karl, «The Law School Curriculum in the1980's: What's Left?», 32 Journal of Legal Education 336 (1982); Gordon, Robert, "Critical Legal Studies as a Teaching Method, Against the Background of the Intellectual Politics of Modern Legal Education in the United States", 1 Legal Education Review 59 (1989).

${ }^{58}$ Grey, Thomas, “Langdell's Orthodoxy», 45 University of Pittsburgh Law Review 1 (1983).

59 Debo pedir disculpas de antemano al lector por el uso descaradamente ambigüo e impreciso que hago a continuación de etiquetas tan manidas como «formalismo", "carácter sustantivo», «positivismo», etc. soy consciente de las dificultades que encierra una utilización tan simplíficada de este tipo de términos, que a menudo confunde más que aclara las cosas y está en la raiz de numerosos malentendidos y de bizantinas discusiones sobre palabras. Sin embargo, ni es éste el lugar ni dispongo ahora de espacio para introducir rigurosas distinciones analíticas en mi discurso, que no quiere ser más que una descripción general de algunas ideas muy básicas en relación con la enseñanza del Derecho, sin pretensiones teóricas «mayores». En el nivel de análisis en que aquí me sitúo, emplearé pues estos términos como lo que en realidad son, simples etiquetas o «símbolos» que sirven para equivocar posturas o corrientes muy diversas y complejas en las que ahora no voy a entrar, ni creo que sea aquí estrictamente necesario hacerio. Dejo en libertad al lector para que interprete esas expresiones según la acepción que más le plazca, ya que a todas ellas me refiero en general cuando aquí las uso: sacrificando el rigor en aras de la brevedad, a mi me basta con que el lector vaya viendo "por donde van los tiros".

60 Dejando de lado la etapa colonial, la historiografía jurídica americana suele emplear una periodización tripartita introducida por Llewellyn en The Common Law Tradition: la etapa que va de la Revolución a la Guerra Civil (período «antebellum»), la etapa que transcurre entre la Guerra Civil y el final de la Primera Guerra Mundial o la aparición del realismo jurídico (período "clásico»), y la etapa actual (a la que podriamos llamar «post-realista»). Durante la primera de estas etapas (circa 1776-1870), caracterizada por lo que Llewellyn llamó el «Grand Style», se arrastra todavía el trasfondo iusnaturalista y populista de la Revolución. Se trata de una "era formativa" (véase Pound, Roscoe, The Formative Era of American Law, 1938) dominada por una concepción «instrumental» más que "formal»" del Derecho y del razonamiento juridico: como escribe Llewellyn, por "formativa" Pound tenía en mente «la creación efectiva de la doctrina que se necesitaba, mediante selección, mediante modificación, mediante invención». El aGrand Style» de esta época aspiraba a reconciliar particulares nociones de «equity» y de «policy», según Llewellyn, se aceptaban los precedentes sólo después de haberlos contrastado, por un lado, con «principios» jurídicos (entendidos «no como meras herramientas para dotar a las reglas de un orden a gran escala» sino como «grandes generalizaciones que deben proporcionar sentido además de orden»); $y$, por otro lado, con razones de «policy" ("en términos de consecuencias previsibles de las reglas»). En suma, el «Grand Style» del Common Law es «una forma de renovación continua del Derecho»), "una armonización operativa de visión y tradición, de continuidad y crecimiento, de maquinaria y propósito, de medida y necesidad" (Lleweilyn, Kari, The Common Law Tradition. Deciding Appeals, Little, Brown and Co., Boston, 1960, pp. 565 en pp. 36-38).

Durante la segunda etapa (circa 1870-1920), según Llewellyn, el "Grand Style» se sustituye por el "Formal Style", cuyo "padre" podría decirse que es Langdell. Pero en Estados Unidos el formalismo jurídico "clásico" (que triunfó más tarde, y durante menos tiempo) nunca llegó a alcanzar los extremos que adquirió en Europa continental. 
Como escribe Robert Gordon, nunca hubo en América tal cosa como «un formalismo puramente lógico-deductivo», o «mecánico», o una «jurisprudencia de máquina de monedas» («Slot-machine jurisprudence»). «Pocos incluso entre los junistas clásicos de Common Law llegaron a ser formalistas cien por cien en el sentido del positivismo o la pandectística de los países de Derecho Civil; nosotros estamos demasiado apegados al caso y a la situación concreta como para eso. Los juristas del Common Law de los`tiempos pre-realistas ciertamente habrían insistido en que la suya era una jurisprudencia de principios, y se hubieran sorprendido ante la idea de que puediera no serlo" (Gordon, Robert, op. Cit., supra nota 57, en p. 1-2). En cuanto a una comparación con la cultura jurídica inglesa, el objetivo principal de todo el libro Atiyah y Summers al que tanto he recurrido en este trabajo es precisamente demostrar la tesis de que el Derecho y la cultura jurídica de Estados Unidos son marcadamente "sustantivos", en comparación con el carácter mucho más «formal»de la tradición juridica inglesa.

${ }^{61}$ Por supuesto, la paradoja a la que me estoy refiriendo se podría disolver dándole la vuelta al argumento: precisamente esa cultura juridica "sustantivista» de Estados Unidos es el caldo de cultivo idóneo par que surjan movimientos como el realista, que en contextos jurídicos mucho más “cerrados» como el Europeo difícilmente podian haber cuajado o haber tenido el mismo peso y alcance.

62 La citå de Bentham está recogida de Friedman, Lawrence (op. Cit, nota 2, enp.108), quien a su vez la recoge de Cook, Charles M., The American Codification Movement: A Study of Antebellum Legal Reform (1981), p.75.

${ }^{63}$ Véase supra, nota 55.

${ }^{64}$ Holmes, Oliver Wendell, «Reviiew of Langdell's A selection of Cases on the law of Contracts», 14 American Law School Review, 233 (1880).

${ }^{65}$ Digo «casi» porque en todo caso, como señala Twining la variedad de las fuentes utilizadas por el case Method siempre permitiría dejar un cierto margen para un "elemento de preferencia, y por tanto de recreación silenciosa, soterrada». Además, el tratamiento de los casos en su secuencia cronológica confiere inevitablemente un cierta concreción y perspectiva histórica al estudio de las reglas jurídicas. Véase Twining William, op. Cit; nota 19, en p. 13 y p. 15. No obstante, aunque Langdell dispone los casos en orden cronológico, lo importante para él es mostrar su secuencia lógica más que cronológica - histórica: se trata de presentar una slínea de casos" bien seleccionados que expresa consistentemente un mismo principio o doctrina, desatendiendo (por «inútiles, o peor que inútiles") otros casos que pudieran contradecir dicha estructura.
${ }^{66}$ La frase es de Friedman, enfatizando la actitud negativa de Langdelll hacia la enseñanza del Derecho como mero aprendizaje de una técnica profesional como antes he señalado. Véase Friedman, op. Cit; nota 52, el p. 289.

67 También Holmes denuncia este hermetismo de Langdell: «Él sólo está por la lógica y odia toda referencia a cualquier cosa que esté fuera de ella, y sus explicaciones y conciliaciones de los casos habrían asombrado a los jueces que los decidieron». Véase Howe, Mark de Wolfe (ed.) Holmes - Pollock, Letters, 17 (1941).

${ }^{68}$ En el discurso de 1886, antes aludido (supra, p. 71). Langdell afirmaba que «el Derecho puede aprenderse y enseñarse en la universidad mediante libros impresos", que «los libros impresos constituye la fuente definitiva de todo el conocimiento jurídicon y que por lo tanto «todo estudiante que pretenda adquinir algún dominio del Derecho como ciencia debe recurrir a estas fuentes "; y añadía: "cla biblioteca es el taller de trabajo propio de los estudiantes y de los profesores por igual; es para nosotros todo lo que los laboratorios de la universidad son para los químicos y los físicos, todo lo que el museo de historia natural es para los Zoólogos, todo lo que el jardín botánico es para los botánicos». No hay que olvidar que los alibros impresos» a que se refiere Langdell no.son otra cosa que los «Casebook», donde no se debía recorrer más que casos jurídicos.

${ }^{69}$ Es un lugar común la crítica contra la «appelate court - itiss de la cultura jurídica americana. Para una versión ya clásica de esta crítica véase por ejemplo la de Frank Law and the Modern Mind 1930 (ed. de 1963, reim, de 1970, Peter Smith, Gloucester, Ma, en pp. Xi - xix); Courts on Trial, 1949 (ed. 1973), Priceton University Press, Princeton, NJ, esp. capitulo XV, «The Upper Court Myth», pp 222 - 224), «Cardozo and the Upper - Court Myth, 13 Law and Contemporany Problems 369 (1948).

70 De todas formas, los libros de "Cases and materials» siguen estando muy lejos de lo que sería un «manual» como los que-se utilizan en España. En Estados Unidos los manuales apenas existen: en las asignaturas de dogmática jurídica se emplean los mencionados "casebooks" (con o sin otros "materials"), y en los demás cursos se reparte a los estudiantes un voluminoso paquete de «readings»: una selección de fotocopias de artículos o fragmentos de libros encabezados por un índice o programa con un calendanio de lecturas para discutir en cada sesión. Una posible explicación de la escasez de manuales es que, desaparecida la lección magistral, los materiales que elaboran los profesores para sus disertaciones, que suelen ser el germen de los manuales, dejan de redactarse, y esas energías se emplean en la preparación de libros de casos. Ni siquiera es corriente que se utilice monografías completas - no ya manuales - como texto básico para un curso. También la publicación de monografias es proporcionalmente escasa en América. No es que en las 
facultades de Derecho Americanas se escriba menos, sino que se publica casi exclusivamente en revistas; aunque eso sí, no es muy raro que los artículos superan las 200 páginas, y un artículo de unas 100 páginas entra todavía dentro de lo normal.

71 En este caracter multidisciplinar de la enseñanza del Derecho, y en la aparición de estos nuevos movimientos (a los que habría que añadir, más recienterrente, "Critical legal Studies», «Feminist Jurisprudence» $y$ «Critical Race Theory») yo creo algo que han debido influir algunos factores «institucionalesn de los que he hablado en la primera parte de este trabajo, como la ausencia de departamentos internos en las facultades de Derecho o, sobre todo, la exigencia de una formación previa en el College: estudiantes llegan a la facultad de Derecho fàmiliarizados ya con algunas de estas otras disciplinas, e incluso los profesores pueden verse inclinados a introducir en su docencia e investigación aquellas disciplinas en las que ellos se especializaron durante el College y cuyo estudio quizá nunca abandonaron del todo (presumiblemente, muchos de los miembros de "Law and Economics" se habían graduado con un «perfil» en economia. Los de "Law and Literature" en literatura, los de "Law and Society» en sociología, etc.).

72 En América, la expresión «legal doctrine» no alude, como su traducción literal nos puede llevar a pensar, a la "doctrina jurídica» entendida estrictamente como la doctrina elaborada por los tratadistas: «legal doctrine" significa simplemente Derecho positivo, o como suelen decir los americanos, «Black- letter Law». Ocurre que en un sistema de Common Law, de Derecho fundamentämente judicial (al menos en sus orígenes) como es el americano, el "Derecho positivo" está formado básicamente por las reglas y "doctrinas" elaboradas por los jueces y tribunales en la fundación de sus sentencias. Esa «doctrina legal», lentamente construida a través de sucesivas sentencias de diversos tribunales, ha de entenderse pues en un sentido muy parecido, si no idéntico, al que empleaba nuestra legislación procesal al recoger como causa de casación la «infracción de doctrina legal». Ahora bien: en América la frontera entre lo que aquí llamaríamos «dogmática jurídica» y su propio objeto de estudio está aún más difuminada que en Europa continental, ya que, como hemos visto, esas doctrinas jurisprudenciales se ven a menudo enniquecidas en su paulatino desarrollo por las interpretaciones y matices introducidas por académicos y juristas de todo tipo, que suelen ser recogidos por los tribunales. Así, la "doctrina» del enriquecimiento injusto es Derecho positivo, plasmado en casos jurisprudenciales y aplicable por los jueces en futuros casos y es a la vez «Doctrina jurídica» en el sentido de que en su construcción también han participado los dogmáticos del Derecho desde las universidades. Quizá ahora se entienda mejor el sentido del término «Doctrina» empleado por Langdell en el pasaje antes citado, y la definición de esa voz ofrecida por el
Black's Law Dictionary (abridged $5^{\text {th }}$ editions, west Publishing Co., St. Paul, Minn, 1993): «una regla, principio, teoría o dogma del Derecho; como la doctrina de la absoción (merger), la doctrina de la relación, etc.».

${ }^{73}$ A veces se ha criticado al case method porque «va demasiado lejos» en esa orientación casi exclusivamente metodológica descuidando en exceso el aprendizaje de reglas. Yo no estoy muy de acuerdo con este tipo dẻ reproches. Por su puesto que un jurista también debe saber normas, pero no es necesanio que sean tantas como las que suelen inyectarse a presión en las memorias de nuestros estudiantes y opositores. Para algo están los libros, y lo verdaderamente importante es aprender a manejarlos, saber qué se puede hacer con las normas que contienen y sobre todo cómo hacerlo. Quizá haya habido casos excepcionales en que se haya incurrido en exceso, pero mi impresión es que en general las facultades de Derecho americanas cumplen sobradamente con la función de «enseñar normas" en la medida necesaria: las reglas y principios básicos sí se aprenden, y la memoria sigue siendo una de las aptitudes esenciales que precisa un estudiante de Derecho (hasta el punto de que, por más que a nosotros nos sorprenda, también es posible escuchar en América críticas precisamente en el sentido contrario: en el de que la enseñanza del Derecho sigue siendo excesivamente memorística).

Por otro lado, la tarea de inculcar normas resulta bastante más complicado en un país como Estados Unidos, donde una facultad de derecho « nacional» difícilmente puede aspirar a enseñar el Derecho de todos y cada uno de los cincuenta Estados, y porque se trata de un sistema de Common Law, donde una buena parte del Derecho no está recogida en códigos o textos legales más o menos sistematizados, sino que ha de ser rastreada a partir de sentencias judiciales que expresan reglas o principios mucho más impresos y flexibles. Mediante el case method, el estudiante aprende sobre todo a extraer por sí mismo. esas reglas y doctrinas, cuyo resultado conforma un cuerpo de Derecho quizá no muy voluminoso pero que es el suyo propio, el producto en buena medida de su razonamiento y de su esfuerzo personal. Quizá hubiera aprendido más cosas si el profesor se las hubiera dado ya hechas, pero las cosas se aprenden mejor mediante la experiencia de hacerlas uno mismo.

${ }^{74}$ Véase Atiyah, P.S., Summers RS., op cit, en nota 1, p.391; Farnsworth, E. Allan, An introduction to the Legal System of the United States, Oceana Publications, New York $2^{\circ}$ ed, 1983, pp 172, en p. 17.

${ }^{75}$ Me parece excesivo afirmar, como hacen ellos, que en el ambiente educativo americano «la fuerza justificatoria del razonamiento de base, y no la autoridad del razonamiento formal, se convierten en el foco primarion. Yo me temo que el formalismo Langelliano enlas facultades de Derecho americanas, aunque de forma menos visible o

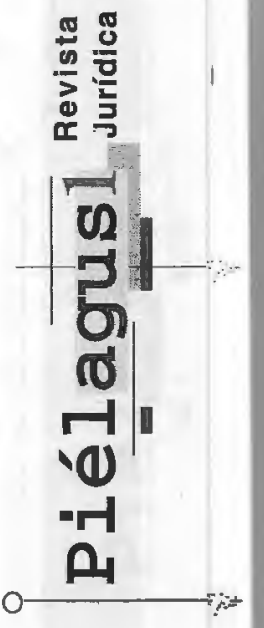


con otros ropajes, sigue estando bastante más vivo de lo que creen estos autores.

${ }^{76}$ Atiyah, P.S,: Summers, R.S., op. Cit supra nota 1, en p 391. Como tambien señala Cavers (citado por estos autores, op. Cit, en p. 390), con el case method los estudiantes «aprenden a ver el Derecho como un instrumento que está continuamente remodelando la sociedad y la economia americana. Dado que los jueces americanos, al escribir sus sentencias, tienden a discutir las «policies políticas, económicas y sociales que tienen que ver con sus decisiones, los estudiantes que han hecho de esas sentencias la base principal de su trabajo durante tres años tienden naturalmente a pensar en la significación de reglas y decisiones jurídicas particulares en términos de «policies» «.

No obstante, esta orientación hacia el epolicy analysis» no está exenta de criticas, dirigidas no ya desde posiciones más o menos «formalistas", sino precisamente desde el flanco contrario. Según estas criticas el "policy analysis" practicado en las facultades de Derecho no esta suficientemente elaborado ni justificado desde un punto de vista teórico general, y tampoco está suficientemente apoyado por investigaciones empíricas concretas. Las razones de «policy no se discute ni argumentan seriamente, sino que se afirman sin más de forma breve y superficial, apelando a un supuesto consenso general sobre determinados valores («la eficiencia en la asignación de recursos*, «la seguridad del tráfico jurídico», "la defensa de la libre competencia y de la productividad „...) o a una supuesta tendencia de desarrollo histórico (« el crecimiento económico", la mayor especialización del trabajo», «la creciente internalización de la economía»...). Estos valores y tendencias constituyen una especie de "sentido común» que se da descontado, una especie de racionalidad funcional inmanente al ordenamiento jurídico y que supuestamente puede resolver los problemas de indeterminación lingüística del Derecho que los realistas habían puesto de relieve, pues se confía en que el jurista - tecnócrata que maneje con habilidad las técnicas del «policy analysis» será capaz de "descubrir» la soluciones socialmente óptimas para prácticamente todos los problemas jurídicos. La racionalidad técnica de esos argumentos de «policy» relativamente estandarizados y acríticamente asumidos sigue ocultando - siempre según este tipo de críticas - las "grandes cuestiones" controvertidas de carácter moral y político en sentido fuerte sobre los términos básicos del orden social. Así, el "policy analysis" puede llegar a ser visto como una puerda falsa a través de la cual se ha introducido un nuevo tipo de "formalismo", en el sentido de que se sigue manteniendo una clara distinción entre el discurso jurídico supuestamente neutral y todavia marcadamente riguroso y determinado (aunque ya no se trate de la racionalidad lógico - deductiva del formalismo clásico), y el discurso valorativo, abiertamente político - moral, que está en la raíz de las discusiones jurídicas.
${ }^{n}$ En las facultades de Derecho americanas los exámenes casi siempre son escritos (rasgo que parece contrastar con el estilo de la docencia); sólo hay uno o a lo sumo dos exámenes por asignatura (téngase en cuenta que la mayonía son cursos cuatrimestrales o semestrales), y suelen concentrarse los de todas las asignaturas en determinados días (no más de 10). Normalmente los exámenes consta de uno o varios casos prácticos sobre los que se plantean diversas preguntas, aunque en cursos sobre materias no estrictamente jurídico - positivas suelen consistir en la exposición de algún tema, o en comentarios de textos. Las alternativas al examen tradicional están muy extendidas, principalmente su sustitución por trabajos de investigación o el llamado «Take home exam», que los estudiantes se llevan a su casa y entregan al cabo de 24 ó 48 horas.

${ }^{78}$ En realidad, el método socrático empieza bastante antes de comerizar la clase: ese «planteamiento del caso» por parte de un estudiante no es otra cosa que la exposición oral, a veces simplemente leyéndolo, del «case brief» o sinopsis del caso, que todos han debido preparar de antemano por escrito en dos o tres páginas. Los «case briefs» han de seguir una técnica estándar que se enseña a los estudiantes durante los primeros días del primer curso (en la asignatura «legal methods» o «legal Writingm), y su elaboración suele ocupar a los estudiantes buena parte de su tiempo fuera de clase (suele haber unas quince horas de clase a la semana, pero para preparar cada una de ellas los estudiantes normalmente invierten dos o tres más). No siempre es fácil hacer un buen «briefw, y aprender a dominar esta técnica es importante para los estudiantes de cara a su futuro ejercicio profesional: es una de las tareas fundamentales que realizan los jóvenes abogados en las "Laws firms», o los "Law clerks" ( ayudantes o pasantes) de jueces o fiscales, y también los profesionales consagrados suelen realizarla por sí mismos para su trabajo.

79 Por eso, dejar copiar a un compañero durante un examen puede acabar afectando negativamente a la nota del estudiante "generoso". Como mecanismo de «autoregulación», no está mal para evitar estos fraudes. El problema es que facilitan una competividad que obstaculiza otras formas de sana cooperación entre los estudiantes (después de una gripe un estudiante puede tener dificultades para que un compañero le preste los apuntes), e incluso llega enrarecer las relaciones personales entre ellos. También hay que decir que ante esta situación los estudiantes suelen reaccionar organizándose espontáneamente en pequeños agrupos de estudio», donde la colaboración es muy intensa, aunque sólo con los compañeros que pertenecen a estos grupos cerrados.

${ }^{80}$ Sobre esta angustia que sufre sobre todo el estudiante de primero de Derecho, y en general sobre el 
mundo de la enseñanza del derecho en Estados Unidos, yo recomiendo al lector cuyo interés sobre este tema no justificaría el esfuerzo de adentrase en el resto de la bibliografía aquí anotada - o quizá ni siquiera el de leer estas páginas - la lectura de una novela. En realidad se trata de un ensayơ autobiográfico "novelado", o de un diario, escrito por Scott Turow, el famoso autor de "best - sellers" tan conocidos como "presunto inocente». La novela se titula One - L (1977, $1^{\text {a }}$ Edición de Wamer Books, 1988, pp.276), título extraído del nombre que en Harvard suele darse a los estudiantes de primer curso de derecho /de "One Law»; los de segundo serian "Two-L's», etc.). Turow cuenta pues su propia experiencia como estudiante de primero de Derecho en Harvard, adoptando a menudo un fuerte tono crítico. Este libro ha sido también un «best - seller», no sólo en los quioscos sino sobre todo entre los profesores y estudiantes de Derecho de todo el País: entre los primeros hay quien lo cita en sus publicaciones, y entre los segundos se ha convertido en la guía extraoficial a los catálogos de orientación de las facultades de Derecho.

81 El verbo ato backbench" es un ingenioso neologismo acuñado hace ya tiempo en la jerga estudiantil de las facultades de Derecho americanas. Hace alusión a la práctica de agazaparse semiclandestinamente de las facultades en los bancos situados en el fondo del aula, con la esperanza de eludir así el peligro de ser llamado a intervenir. La asignación individualizada de los asientos y el diagrama del aula utilizado por el profesor intentan combatir esta práctica.

${ }^{82} \mathrm{El}$ «n 6 - hassie pass" es una reinvindicación relativamente "reciente de cierto sector del alumnado. Evocando los «Miranda rights" - los derechos del detenido reconocidos en Miranda v. Arizona, 384 U.S.436, (1966)-, consiste en el «derecho a no hablar» de un estudiante cuando es interrogado por el profesor, sin tener más explicaicones sobre su negativa ni soportar el posible ensañamiento con el que éste podría presionarle para que conteste: el estudiante dice simplemente «paso» y el profesor debe dirigirse rápidamente y con toda naturalidad a otros estudiante.

83 Una de las razones que explican que el case method sea un método más crítico - aparte, por supuesto, de que las cosas se discuten en clase - es el carácter necesariamente comparativo del estudio de los casos en un sistema federal como el americano: el estudiante no puede aceptar como definitiva la solución dada por el juez en el caso que tiene entre manos, porque, como dice Cavers, «el próximo caso que lea puede haber sido extraído de los repertorios de jurisprudencia de otro Estado, que adopta una posición diametralmente opuesta". No hay que olvidar que en Estados Unidos no existe un sistema jurisdiccional unitario con una estructura estrictamente jerarquizada en el que la doctrina junisprudencial emana o se unifica desde arriba (como en el caso de nuestro Tribunal Supremo): los tribunales de los diferentes Estados pueden llegar a soluciones distintas y dotadas de firmeza sobre el mismo problema.

${ }^{84}$ He aquí un puñado de esas críticas: el divorcio existente entre docencia e investigación; la orientación profesional de las facultades como fábrica de abogados para el mundo de los grandes negocios; la marginación en el curriculum de las materias "políticas" o críticas frente a la centralidad de las producen y legitiman el modelo existente en norteamerica; el apolicticismo tecnocrático de la concepción dominante sobre lo que es upensar como un jurista» (o el «neoformlsimo» disfrazado de argumetnos de «policy» estandarizados y acríticamente asumidos, que ocultan la raíz político - moral del discurso jurídico); la precariedad de la "enseñanza clínica»; el «nivel intermedio» de la enseñanza, que ni forma buenos técnicos para el ejercicio ni buenos juristas con una sólida formación teórica; diversos defectos del sistema menitocrático de admisión de estudiantes; la timidez en la aplicación de políticas de "acción afirmativa» en favor de las minorias raciales; el ambiente emocional represivo, jerarquizado y competitivo que se crea en las aulas....

\section{Juan Antonio Pérez Lledó}

\section{Licenciado en Derecho y Premio Extraordinario de Licenciatura de la Universidad Alicante (España). Doctor en Derecho con Premio Extraordinario de Doctorado(1994).}

